\title{
Profile and Outcome of Triple Negative Breast Cancer at a Tertiary Care University Hospital in Nepal
}

\author{
Suman Khanal', Yogendra P. Singh ${ }^{1}$, Gita Sayami², Akihiko Ozaki ${ }^{3}$
}

${ }^{1}$ Department of GI and General Surgery, Tribhuvan University Teaching Hospital, Kathmandu, Nepal. ${ }^{2}$ Department of Pathology, Tribhuvan University Teaching Hospital, Kathmandu, Nepal. ${ }^{3}$ Department of Breast Surgery, Jyoban Hospital of Tokiwa Foundation, Fukushima, Japan.

\begin{abstract}
Background: TNBC (Triple negative breast cancer) subtype (ER-/PR-/HER2-) of breast cancers are known for aggressive tumor biology and poor survival prospects, with high early relapse rate. However, little is known about the prevalence and characteristics of TNBC breast cancer in Nepal. Objectives: To clarify the geographical distribution, clinical profile and outcome of TNBC patients when compared with non-TNBC patients managed in tertiary care university hospital in Nepal. Materials and Methods: This is a study on prospective observational analyses of TNBC and non-TNBC patients managed at Tribhuvan University Teaching Hospital, Kathmandu from October 2015-March 2018. We collected and analyzed data on clinical profile, pathological tumor features and outcome of the two patient groups. Results: A total of 108 breast cancer patients were included in our study, $38(35.2 \%)$ of which were TNBCs. Mean age at diagnosis was $49 \pm 12$ years. Majority of TNBCs $(29 \%)$ were concentrated in Terai districts compared to non-TNBCs (18.6\%). Among TNBCs, $15.2 \%$ had tumor size $5 \mathrm{~cm}$ or more while only $11.9 \%$ had such finding in non-TNBCs. Majority of TNBCs and non-TNBCs were of invasive ductal carcinoma of NST histology ( $76.3 \mathrm{vs} 90 \%$ ). TNBC tumors were significantly of grade 3 ( $\mathrm{P}$ value $=0.003$ ). Perineural invasion was seen more (15.8\%) in TNBCs compared to $8.96 \%$ in non-TNBCs. On average, $23.6 \%$ of total nodes retrieved from axilla were positive for tumor in TNBCs compared to $21 \%$ in non-TNBCs. Three patients developed metastases in TNBCs of which two were to brain while 5 had metastases in non-TNBC with none to brain. Higher percentage of patients died in TNBC group (13.2 vs 7.1\%). Conclusions: TNBCs are quite common, higher grade tumors with brain metastasis without particular geographic distribution.
\end{abstract}

Keywords: Breast cancer- invasive ductal- triple negative

Asian Pac J Cancer Care, 5 (2), 101-105

\section{Introduction}

Breast cancer is the most frequent cancer among women affecting 1.5 million people worldwide with greatest number of cancer related deaths [1]. In 2015, it accounted for approximately $15 \%$ of all cancer deaths among women [1]. Triple-negative breast cancer (TNBC) is a molecular subtype of breast cancer in which the estrogen receptor and progesterone receptor are not expressed, and human epidermal growth factor receptor 2 is not amplified or overexpressed [2]. This subtype accounts for $10-24 \%$ of breast cancer and is known for worse prognosis with early relapse compared with other subtypes of breast cancer [3-5]. The epigenetic epithelial to mesenchymal transition in TNBC could explain its high
Submission Date: 02/27/2020Ａcceptance Date: 05/05/2020

Corresponding Author:

Dr. Suman Khanal

Department of GI and General Surgery, Tribhuvan University Teaching Hospital, Kathmandu, Nepal.

Email: sumandoc@iom.edu.np 
grade, recurrence, metastasis and mortality.

\section{Materials and Methods}

\section{Study setting, participants, and variables}

This study was done at a tertiary care Tribhuvan University Teaching Hospital (TUTH), located at central region of Nepal, Kathmandu. In our clinical practice, all the breast cancer patients undergo fine needle aspiration cytology (FNAC) in early breast cancer and core needle biopsy (CNB) in locally advanced cases. Patients with early breast cancer undergo surgery (breast conserving surgery (BCS), oncoplasty or modified radical mastectomy) followed by chemotherapy with or without radiotherapy and adjuvant hormonal therapy for hormone positive cases. Those with locally advanced cases receive neoadjuvant chemotherapy to downstage tumor followed by surgery and radiotherapy. Hormone positive cases receive hormonal therapy. Metastatic cases are treated palliatively.

We considered a total of 140 histopathologically confirmed non-metastatic cases of breast cancer patients managed in our hospital from October 2015-March 2018. We performed a follow-up of these patients until December 2018 in determining their outcomes. Using the medical records, we collected data on age, ethnicity, district, menopausal status, histology, tumor size, grade, lymphovascular invasion, perineural invasion, lymph node status, neoadjuvant chemotherapy, pathological stage, recurrence, metastasis and mortality.

Staging was done with chest $\mathrm{x}$-ray, ultrasound of abdomen and pelvis for early disease with the addition of computed tomography (CT) and MRI for locally advanced cases. TNBC was defined as ER negative, PR negative and HER2 neu 0/1+ cancers. A tumor was classified negative when ER and PR expression was $<1 \%$ in tumor cell nuclei. HER2 neu 2+ were considered equivocal/borderline [16] that needed FISH for confirmation but due to high costs and availability, were rarely done. HER 2 neu $2+$ cases were thus excluded from the study. Our treatment practices at two specialized cancer hospitals also show that targeted therapy against HER2 neu are rarely used due to forbidding high costs. For receptor status determination, it was done on Trucut biopsy sample in cases who received neoadjuvant therapy while it was done on specimen who received surgery first.

\section{Data analysis}

The categorical data was analyzed using chi-squared/ fisher's exact test where deemed appropriate. Unpaired t-test was applied for comparison for numerical data. $\mathrm{R}$ version 3.6.1 was used to analyze the data, plot the geographical mappings; P value $<0.05$ was considered significant.

\section{Ethical clearance}

Ethical clearance was obtained from Institutional Review Board at the Tribhuvan University Teaching Hospital and consent was taken from all patients.

\section{Results}

Figure 1 shows the process in which we chose the patients for the study. After excluding cases with no receptor status data, HER2 neu equivocal cases and a case of squamous cell carcinoma, total of 108 cases were enrolled in the study.

Table 1 shows the patient characteristics. Out of 108 cases studied at our institute, 38 cases $(35.2 \%)$ were TNBC. Mean age at diagnosis was $49 \pm 12$ years in TNBC group as compared to $50 \pm 11$ years in non-TNBCs ( $\mathrm{P}$ value $=0.88$ ). Three patients in non-TNBC were males while TNBCs were all females. Eight of $38(21.1 \%)$ TNBC and 13 of $70(18.6 \%)$ non-TNBC patients were 40 years or younger (Table 1$)$.

TNBC prevalence was $43.6 \%(24 / 55)$ in Indo-Aryans vs $26.4 \%$ (14/53) in Tibeto-Burman. Though it suggests higher percentage of TNBC among Indo-Aryans, it was not significantly different, and it could be expected, as their population share is $79 \%$ according to 2011 census of Nepal.

Geographically TNBC patients were concentrated more in southern districts of Nepal (29\%) compared to non-TNBCs $(18.6 \%)$ though it was not statistically significant (Figure 2 and Figure 3).

Among TNBCs, $57.9 \%$ and among non-TNBCs, 53.7\% were premenopausal. Greater proportion of patients was of invasive ductal carcinoma, no special type in TNBCs (76.3\%) against $90 \%$ in non-TNBC. It was however not statistically different $(\mathrm{P}$ value $=0.10)$. The second most common histology in TNBC was invasive carcinoma with medullary features while it was ductal carcinoma in situ (DCIS) in non-TNBC (Table 2).

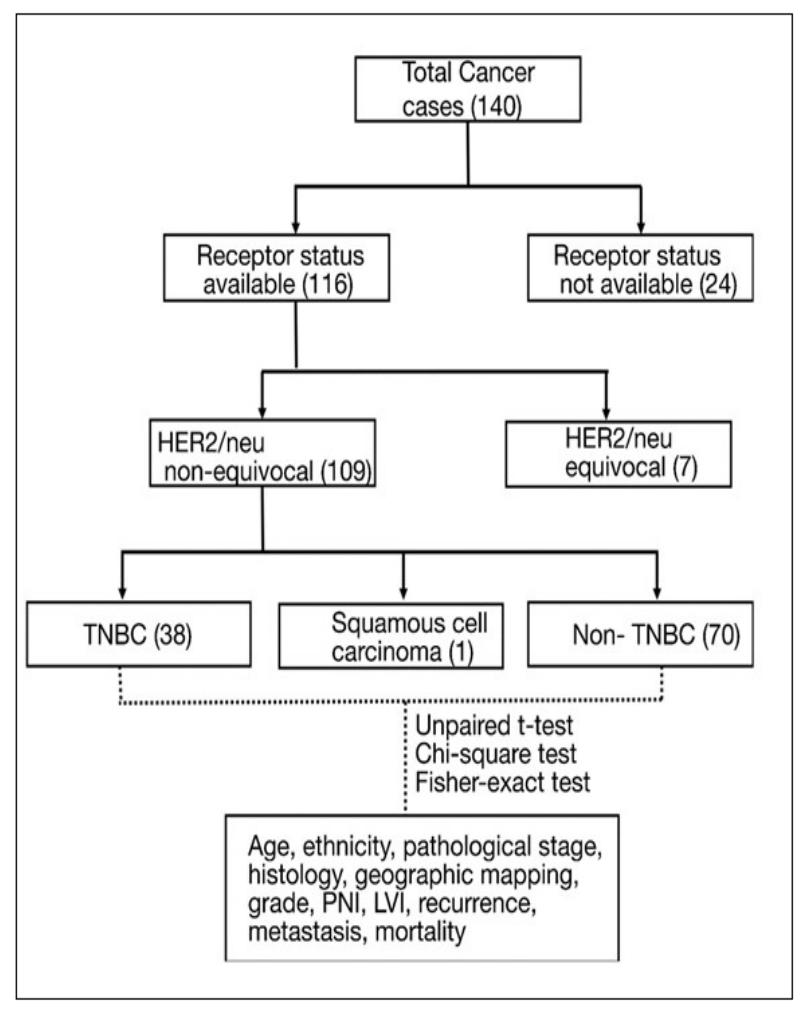

Figure 1. Patient Enrollment 
Table 1. Comparison of Patient and Tumor Characteristics

\begin{tabular}{lccc}
\hline & TNBC & Non-TNBC & P value \\
\hline Mean age at diagnosis (years) & $49 \pm 12$ & $50 \pm 11$ & 0.88 \\
$\leq 40$ years & $8(21.1 \%)$ & $13(18.6 \%)$ & 0.95 \\
Tibeto-Burman & $14(36.8 \%)$ & $39(55.7 \%)$ & 0.09 \\
Terai districts & $11(29 \%)$ & $13(18.6 \%)$ & 0.32 \\
Premenopausal & $22(57.9 \%)$ & $36(53.7 \%)$ & 0.46 \\
Invasive ductal carcinoma, NST & $29(76.3 \%)$ & $63(90 \%)$ & 0.10 \\
Tumor size $\geq 5 \mathrm{~cm}$ & $5(15.2 \%)$ & $7(11.9 \%)$ & 0.90 \\
Grade 3 histology & $12(31.6 \%)$ & $5(7.5 \%)$ & 0.003 \\
Lymphovascular invasion & $18(47.4 \%)$ & $39(58.2 \%)$ & 0.39 \\
Perineural invasion & $6(15.8 \%)$ & $6(8.96 \%)$ & 0.46 \\
Lymph node metastasis & $17(51.5 \%)$ & $28(47.5 \%)$ & 0.88 \\
Pathological stage 3 & $14(42.4 \%)$ & $20(33.9 \%)$ & 0.56 \\
Locoregional recurrence & $1(2.6 \%)$ & $4(5.7 \%)$ & 0.8 \\
Metastasis & $3(7.9 \%)$ & $5(7.1 \%)$ & 1 \\
Mortality & $5(13.2 \%)$ & $5(7.1 \%)$ & 0.5 \\
\hline
\end{tabular}

Table 2. Distribution of Histological Types

\begin{tabular}{lcll}
\hline TNBC & \multicolumn{2}{l}{ Non-TNBC } \\
\hline Histological type & Number & Histological type \\
Invasive CA NST & 29 & Invasive CA NST \\
Invasive CA with medullary features & 4 & DCIS & Number \\
Invasive CA with mucinous component & 2 & Invasive lobular carcinoma \\
Metaplastic carcinoma & 1 & Invasive carcinoma with apocrine differentiation \\
Mixed invasive CA NST + Invasive lobular carcinoma & 1 & Solid papillary carcinoma \\
Mucinous carcinoma & 1 & & \\
\hline
\end{tabular}

TNBCs had higher percentage $(15.2 \%)$ of tumors with pathological tumor size $5 \mathrm{~cm}$ or more while $11.9 \%$ had such finding in non-TNBCs though it was not statistically significant $(\mathrm{P}$ value $=0.90)$. The cases who received neoadjuvant therapy were not considered for pathological tumor size evaluation. Five and eleven patients had received neoadjuvant chemotherapy in TNBC and non-TNBC respectively.

Tumors were of higher grade (Grade 3 ) in $31.6 \%$ in

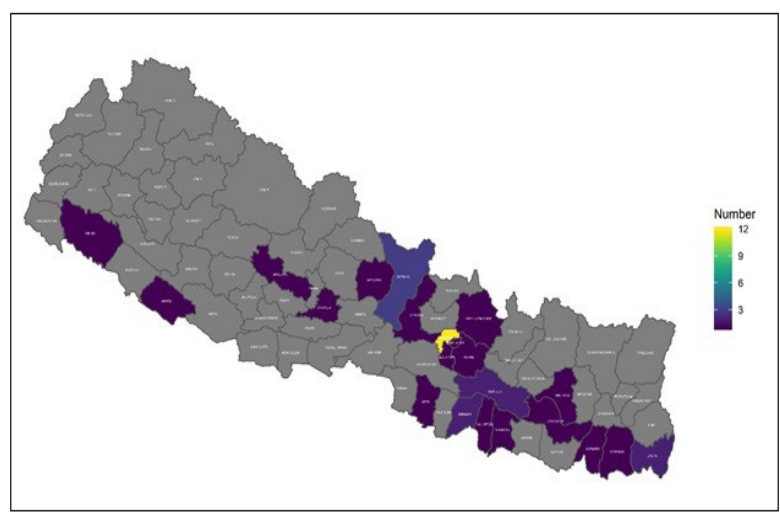

Figure 2. Geographic Distribution of TNBC Patients Across the Districts
TNBCs against only $7.5 \%$ in non-TNBCs, which was statistically significant $(\mathrm{P}$ value $=0.003)$. Lymphovascular invasion (LVI) was seen in $47.4 \%$ of TNBCs compared to $58.2 \%$ in non-TNBCs (P value $=0.39)$. Perineural invasion (PNI) was seen more (15.8\%) in TNBCs compared to $8.96 \%$ in non-TNBCs. It was however not statistically significant $(\mathrm{P}$ value=0.46). For uniformity, three cases with DCIS in non-TNBC were excluded from tumor grade, lymphovascular invasion and perineural invasion analysis.

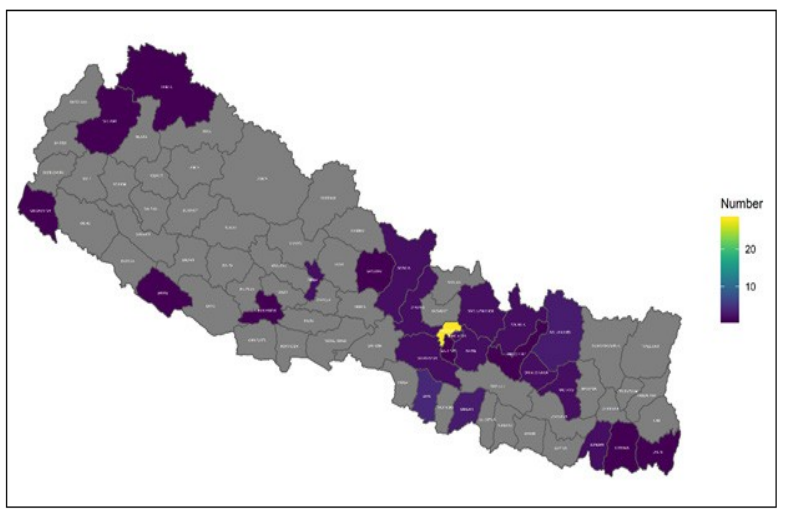

Figure 3. Geographic Distribution of Non-TNBC Patients Across the Districts 
Excluding cases who received neoadjuvant chemotherapy, lymph node metastases were present in $51.5 \%$ cases in TNBC and $47.5 \%$ in non-TNBC. On average, $23.6 \%$ of total nodes retrieved from axilla were positive for tumor compared to $21 \%$ in non-TNBCs. Among TNBCs, $42.4 \%$ presented at pathological stage 3 while only $33.9 \%$ of non-TNBCs presented at this stage ( $P$ value $=0.56$ ).

One patient developed locoregional recurrence in TNBC (2.6\%) against four in non-TNBC (5.7\%). Three patients developed metastasis in TNBC $(7.9 \%)$, one to abdomen and two to brain while none developed metastasis to brain in non-TNBC. In fact, among five (7.1\%) who developed metastasis in non-TNBC, two were to bone and liver both, two to bone only and one to liver only. All metastases along with additional two cases died in TNBC (13.2\%) while five cases succumbed in non-TNBC (7.1\%).

\section{Discussion}

This study was done to evaluate the geographical distribution, demographic profile and tumor characteristics of TNBCs and compare them with non-TNBCs.

Our study identified $35.2 \%$ of breast cancer to be TNBC cases, which is consistent with previous literature suggesting higher cases of TNBC in South Asian countries (Nepal [17] and North India [18]) compared to $10-24 \%$ in the West [3-4]. However it was less than the incidence of $41.3 \%$ reported in another study in Nepal [15]. Both of our groups had lower number of patients 40 years or below but percent of total nodes positive for tumor was higher in this younger group $39.5 \%$ in TNBC and $33.2 \%$ in non-TNBC). Literature shows that breast cancer in young patients are often triple negative [14-19] but our study and a study in large cohort in Brazil does not support it [20]. TNBCs are noted to occur in younger blacks and Hispanics in the west [19-21]. In our setup, TNBC was more prevalent in Indo-Aryans, though the difference was not statistically significant. There was no literature evaluating this difference in Nepal.

Though statistically insignificant, geographic mapping of cancer cases showed TNBC to be more concentrated towards Terai districts. Terai districts are relatively hotter and as expected receive more sunlight due to their closeness to equator. One study from Turkey had found similar finding [22]. It would be very interesting to do a prospective study in a large cohort to test this hypothesis.

TNBCs are reported to be more common among pre-menopausal females [21-23-24]. However, this finding was not seen in our study, and neither the number of premenopausal females was high among TNBC.

Majority of TNBCs were invasive carcinomas of no special type similar to other studies [5-24-25]. Even the majority of non-TNBC were also invasive carcinomas of no special type similar to a study in Brazil [20].

Perineural invasion was seen more in TNBC group and lymphovascular invasion in non-TNBC, though it was not significantly different. Lymph node involvement was similar in two groups similar to a study in Brazil [20].
Many studies cite TNBC to be larger than non-TNBC [21-26]. However in our study, taking the cutoff of $5 \mathrm{~cm}$, tumor size was not significantly different in two groups. In a study done in Brazil, even while taking a lower threshold of $2 \mathrm{~cm}$, two groups were not significantly different at $95 \%$ significance [20]. TNBC tumors in our cohort was significantly of higher grade (Grade 3 ) which is consistent with other studies [19-21-24-27]. Also, TNBC had aggressive histological types like invasive carcinoma with medullary features and metaplastic carcinoma. Even in a multimodal annual screening done to detect cancer cases, grade 3 cancers were more in TNBC [28].

Many studies report the percentage of patients with positive axillary lymph nodes. We calculated average percentage of positive nodes out of total nodes retrieved from axilla. It was however not different between two groups. It would be interesting to evaluate this variable in large cohort. Number of recurrence and metastasis were similar in two groups similar to study in Brazil [20]. Interesting to note was two patients in TNBC cohort who had brain metastasis while none had in non-TNBC. This was as expected in the literature [21-26-29]. Mortality, though high in TNBC, was not statistically different in contrast to studies which report high mortality and early recurrence in TNBC [20-21-26]. This could be due to our small sample size and short follow up.

The main limitation was that the study center was a single center study which, might not represent all patients receiving treatment across Nepal.

In conclusion, TNBCs are quite common, higher grade tumors with brain metastasis without particular geographic distribution.

\section{Acknowledgements}

We would like to thank Research Department of Tribhuvan University Teaching Hospital which supported this work.

\section{Funding statement}

There was no source of funding for this research.

\section{References}

1. WHO | Breast cancer. (n.d.). WHO. Retrieved February 28, 2018, from http://www.who.int/cancer/prevention/ diagnosis-screening/breast-cancer/en/ [

2. Marotti JD, de Abreu FB, Wells WA, Tsongalis GJ. TripleNegative Breast Cancer: Next-Generation Sequencing for Target Identification. The American journal of pathology. 2017;187(10):2133-8.

3. Dawood S. Triple-negative breast cancer: epidemiology and management options. Drugs. 2010;70(17):2247-58.

4. Jitariu AA, Cimpean AM, Ribatti D, Raica M. Triple negative breast cancer: the kiss of death. Oncotarget. 2017;8(28):46652-62.

5. Schmadeka R, Harmon BE, Singh M. Triple-negative breast carcinoma: current and emerging concepts. American journal of clinical pathology. 2014;141(4):462-77.

6. Sikandar SS, Kuo AH, Kalisky T, Cai S, Zabala M, Hsieh $\mathrm{RW}$, et al. Role of epithelial to mesenchymal transition 
associated genes in mammary gland regeneration and breast tumorigenesis. Nature communications. 2017;8(1):1669.

7. Su Y, Hopfinger NR, Nguyen TD, Pogash TJ, SantucciPereira J, Russo J. Epigenetic reprogramming of epithelial mesenchymal transition in triple negative breast cancer cells with DNA methyltransferase and histone deacetylase inhibitors. Journal of experimental \& clinical cancer research: CR. 2018;37(1):314.

8. Yang J, Mani SA, Donaher JL, Ramaswamy S, Itzykson RA, Come C, et al. Twist, a master regulator of morphogenesis, plays an essential role in tumor metastasis. Cell. 2004;117(7):927-39.

9. Carey LA, Dees EC, Sawyer L, Gatti L, Moore DT, Collichio $\mathrm{F}$, et al. The triple negative paradox: primary tumor chemosensitivity of breast cancer subtypes. Clinical cancer research : an official journal of the American Association for Cancer Research. 2007;13(8):2329-34.

10. Liedtke C, Mazouni C, Hess KR, Andre F, Tordai A, Mejia $\mathrm{JA}$, et al. Response to neoadjuvant therapy and long-term survival in patients with triple-negative breast cancer. Journal of clinical oncology : official journal of the American Society of Clinical Oncology. 2008;26(8):1275-81.

11. Park JH, Ahn JH, Kim SB. How shall we treat early triplenegative breast cancer (TNBC): from the current standard to upcoming immuno-molecular strategies. ESMO open. 2018;3(Suppl 1):e000357.

12. GLOBOCAN. IARC https://gco.iarc.fr/today/data/factsheets/ populations/524-nepal-fact-sheets.pdf2018 [

13. Singh YP, Sayami P. Management of breast cancer in Nepal. JNMA; journal of the Nepal Medical Association. 2009;48(175):252-7.

14. Acharya SC, Jha AK, Manandhar T. Clinical profile of patients presenting with breast cancer in Nepal. Kathmandu University medical journal (KUMJ). 2012;10(39):3-7.

15. Nepal B, Singh, Y., Sayami, P., \& Sayami, G. An institutional review of tumour biology of breast cancer in young Nepalese women. Journal of Society of Surgeons of Nepal. 2017;18(2):16-9.

16. Wolff AC, Hammond ME, Schwartz JN, Hagerty KL, Allred DC, Cote RJ, et al. American Society of Clinical Oncology/College of American Pathologists guideline recommendations for human epidermal growth factor receptor 2 testing in breast cancer. Journal of clinical oncology : official journal of the American Society of Clinical Oncology. 2007;25(1):118-45.

17. Gupta M, Khanna, S., Kumar, M., Kar, A. G., \& Gupta, S. K. Epidemiological Study of Triple-Negative Breast Cancer Patients in North Indian Population: A Hospital-Based Study. Indian Journal of Surgical Oncology 2017;8(3):279-83.

18. Shakya S. Epidemiology and clinical profile of breast cancer in central Nepal: A single institutional experience. Journal of Clinical Oncology. 2017;35((15_suppl)):e12008-e.

19. Bauer KR, Brown M, Cress RD, Parise CA, Caggiano V. Descriptive analysis of estrogen receptor (ER)-negative, progesterone receptor (PR)-negative, and HER2-negative invasive breast cancer, the so-called triple-negative phenotype: a population-based study from the California cancer Registry. Cancer. 2007;109(9):1721-8.

20. Goncalves H, Jr., Guerra MR, Duarte Cintra JR, Fayer VA, Brum IV, Bustamante Teixeira MT. Survival Study of Triple-Negative and Non-Triple-Negative Breast Cancer in a Brazilian Cohort. Clinical Medicine Insights Oncology. 2018;12:1179554918790563.

21. Foulkes WD, Smith, I. E., \& Reis-Filho, J. S. TripleNegative Breast Cancer New England Journal of Medicine. 2010;363(20):1938-48.
22. Mutlu H, Buyukcelik A, Colak T, Ozdogan M, Erden A, Aslan T, et al. Is sunlight a predisposing factor for triple negative breast cancer in Turkey? Asian Pacific journal of cancer prevention : APJCP. 2013;14(2):801-3.

23. Boyle P. Triple-negative breast cancer: epidemiological considerations and recommendations. Annals of oncology: official journal of the European Society for Medical Oncology. 2012;23 Suppl 6:vi7-12.

24. Carey LA, Perou CM, Livasy CA, Dressler LG, Cowan $\mathrm{D}$, Conway $\mathrm{K}$, et al. Race, breast cancer subtypes, and survival in the Carolina Breast Cancer Study. Jama. 2006;295(21):2492-502.

25. Carey L, Winer E, Viale G, Cameron D, Gianni L. Triplenegative breast cancer: disease entity or title of convenience? Nature reviews Clinical oncology. 2010;7(12):683-92.

26. Elsawaf Z, Sinn HP. Triple-Negative Breast Cancer: Clinical and Histological Correlations. Breast care (Basel, Switzerland). 2011;6(4):273-8.

27. Kreike B, van Kouwenhove M, Horlings H, Weigelt B, Peterse $\mathrm{H}$, Bartelink $\mathrm{H}$, et al. Gene expression profiling and histopathological characterization of triple-negative/ basal-like breast carcinomas. Breast cancer research : BCR. 2007;9(5):R65.

28. Podo F, Santoro F, Di Leo G, Manoukian S, de Giacomi $\mathrm{C}$, Corcione $\mathrm{S}$, et al. Triple-Negative versus Non-TripleNegative Breast Cancers in High-Risk Women: Phenotype Features and Survival from the HIBCRIT-1 MRI-Including Screening Study. Clinical cancer research : an official journal of the American Association for Cancer Research. 2016;22(4):895-904.

29. Heitz F, Harter P, Lueck HJ, Fissler-Eckhoff A, LorenzSalehi F, Scheil-Bertram S, et al. Triple-negative and HER2overexpressing breast cancers exhibit an elevated risk and an earlier occurrence of cerebral metastases. European journal of cancer (Oxford, England: 1990). 2009;45(16):2792-8.

\section{(i) (2)}

This work is licensed under a Creative Commons AttributionNon Commercial 4.0 International License. 